\title{
Radiolabelled lymphocyte migration in rheumatoid synovitis
}

\author{
C Jorgensen, I Couret, C Bologna, M Rossi, J Sany
}

\begin{abstract}
Objectives-To study the ability of technetium-99m hexamethyl propylene amineoxime (HMPAO) labelled lymphocyte scintigraphy to quantify synovial inflammation, and to analyse the kinetics of lymphocyte retention in the joints of patients with rheumatoid arthritis (RA). Methods-After isolation of the lymphocytes, the cells were radiolabelled in vitro with $250 \mathrm{MBq}{ }^{99 m}$ Tc-HMPAO. The scans were performed 30 minutes, three hours and 20 hours after injection.

Results-An increase of the scintigram signal obtained at 20 hours was associated with a high joint swelling and joint pain score ( $F$ test $=3.07, p<0.002)$, but not with the radiological score. A positive joint scintigram was predictive of active synovitis. Although the scintigram variation over time did not reach statistical significance, the kinetics of the scintigram signal tended to differ according to the disease duration: in early $R A$, active arthritis could be clearly imaged as early as 30 minutes, increased at three hours and the signal intensity persisted at 20 hours. In contrast, in long standing disease, the affected joints were imaged at 30 minutes, persisted unchanged at three hours, and the scintigram score decreased significantly at 20 hours.

Conclusions-The study shows that ${ }^{99 \mathrm{~m}} \mathrm{Tc}$ HMPAO joint scintigraphy may be used to detect and to localise active rheumatoid arthritis.
\end{abstract}

(Ann Rheum Dis 1995; 54: 39-44)

Service d'ImmunoRhumatologie, Centre Gui-deChauliac, Montpellier, France C Jorgensen C Bologna J Sany

Service de Médecine Nucléaire, Hôpital Lapeyronie, Montpellier, France I Couret

M Ross

Correspondence to: Dr C Jorgensen, Service d'ImmunoRhumatologie, Centre Gui-de-Chauliac, 34059 Montpellier Cedex, France.
Rheumatoid arthritis (RA) is an autoimmune disease in which joint inflammation is mediated through helper-inducer lymphocytes. ${ }^{1}$ The retention of circulating lymphocytes in the joints is regulated by the expression of adhesion molecules, and the critical step is the ability of endothelial cells to act as an adhesive surface for migrating lymphocytes. ${ }^{2}$ Cytokines produced at the inflammatory site enhance the adhesion of leucocytes to endothelial cells by inducing the expression of endothelial leucocyte adhesion molecules, intercellular adhesion molecules (ICAM), vascular cellular adhesion molecules, and $\beta 1$-integrin expression on lymphocytes. ${ }^{34}$ Initially, the $\mathrm{T}$ lymphocyte infiltration in the synovial membrane seems to be selective and limited, but in long standing disease, polyclonal lymphocytes accumulate within the joints without specificity. ${ }^{5}{ }^{6}$ This suggests that the joint retention of lymphocytes in RA must fluctuate with the stages of the disease.

The evaluation of inflammation in arthritic joints is a matter of subjective judgment, and therefore has poor reproducibility. An accurate assessment to detect and quantify the lymphocyte inflammation in RA is clearly needed. Different isotope tracer techniques with various biological compounds have been used to assess joint inflammation in the disease. Radiolabelled immunoglobulin scintigraphy seems to be a sensitive method to evaluate inflamed joints, without specificity. ${ }^{7}$ In $\mathrm{RA}$, indium-111 labelled polynuclear neutrophil joint scintigraphy was reliable in acute inflammation, but false negative results were observed in patients with prolonged illness. Furthermore, the indium-111 leucocyte uptake did not clearly change between the different times of measurement, and no information on the kinetics of leucocyte accumulation in the joints was available. ${ }^{8} \mathrm{We}$ describe for the first time the use of technetium-99m hexamethylpropylene amineoxime (HMPAO) radiolabelled lymphocyte scintigraphy in RA.

\section{Patients and methods}

PATIENTS

Eight patients with definite RA according to the American Association Criteria were selected. ${ }^{9}$ They were six women and two men; the mean (SD) age was 63.5 (4) years. Their disease duration ranged from eight months to 22 years. Rheumatoid factor was present in six of the patients. All patients were being treated with non-steroidal anti-inflammatory drugs, and six with disease modifying anti-rheumatic drugs (three with parenteral gold, two with methotrexate and one with sulphasalazine). Synovial histology was available in three patients who had surgery after the scintigraphy. Table 1 summarises the general characteristics of the patients. Informed consent was obtained from all patients.

\section{JOINT EVALUATION}

For each patient, 12 joints (right and left wrist, elbow, shoulder, hip, knee, ankle) were evaluated by one of us; a total of 96 joint 
Table 1 General characteristics of the patients

\begin{tabular}{llllrll}
\hline Patients & Sex & $\begin{array}{l}\text { Age } \\
\text { (years) }\end{array}$ & $\begin{array}{l}\text { Disease } \\
\text { duration } \\
\text { (years) }\end{array}$ & $\begin{array}{l}E S R \\
(\mathrm{~mm} / \mathrm{h})\end{array}$ & $R F$ Histology \\
\hline 1 & $\mathrm{~F}$ & 67 & 8 & 72 & + & +++ lym infil \\
2 & $\mathrm{~F}$ & 60 & 22 & 21 & - & fibrosis \\
3 & $\mathrm{~F}$ & 65 & 11 & 5 & - & ND \\
4 & $\mathrm{~F}$ & 70 & 12 & 65 & + & ND \\
5 & $\mathrm{M}$ & 63 & 5 & 94 & + & ND \\
6 & $\mathrm{M}$ & 60 & 8 months & 100 & + & +++ lym infil \\
7 & $\mathrm{~F}$ & 65 & 10 months & 50 & + & ND \\
8 & $\mathrm{~F}$ & 58 & 4 & 100 & + & ND \\
\hline
\end{tabular}

$\mathrm{RF}+=$ titre of rheumatoid factor $>40$ UI on nephelometry; $\mathrm{ESR}=$ erythrocyte sedimentation rate; $\mathrm{ND}=$ not done. Lym infil = lymphocyte infiltration of synovial membrane.

evaluations were available. All joints were scored separately for pain and for swelling on a 4 point scale, from 0 (absence of pain or swelling), to 3 (very painful or highly swollen joint). Active inflammation within a joint was considered present if scores for pain and swelling were above 2 . Conventional radiographs of each affected joint were obtained; erosions and joint space narrowing were scored 'blind' to minimise interobserver variation, according to the Larsen's score (from $0=$ normal joint to $5=$ joint destruction). ${ }^{10}$

\section{LYMPHOCYTE LABELLING}

A sample of $120 \mathrm{ml}$ heparinised whole blood was obtained from each patient. Mononuclear cells were isolated on Ficoll gradient (FicollPaque, Pharmacia, Uppsala, Sweden) and labelled with mean (SD) 280 (100) $\mathrm{mBq}$ ${ }^{99 \mathrm{~m}}$ Tc-HMPAO (Peters Loncet) and $130 \times 10^{6}$ (range $80-190 \times 10^{6}$ ) mononuclear cells were injected intravenously. The amount of ${ }^{99 \mathrm{~m}} \mathrm{Tc}$ eluted from labelled cells was determined by incubating $10 \times 10^{6}$ labelled cells at $37^{\circ} \mathrm{C}$ with $5 \%$ carbon dioxide in $3 \mathrm{ml}$ RPMI 1640 (Gibco), and $10 \%$ fetal calf serum, for up to 20 hours. A large view gamma camera Sopha DSX (Sopha medical) was used, and images were acquired in a 128-128 matrix; static images contained 300000 counts. The patients were positioned ventral side facing the low energy, high resolution collimator, and serial scintigrams were carried out immediately. Images were acquired at 30 minutes, three hours and 20 hours after injection. For each patient, the following six joints were scored on each side: wrist, elbow, shoulder, hip, knees, and ankles. For each scan acquisition time, the region of interest (ROI) was placed over the joints, and the activity per pixel within the ROI was determined. To correct for background tissue activity, an ROI was applied over the adjacent muscle tissue beside the joint, and background tissue activity per pixel determined. An objective score was determined from the scintigrams, defined as counts per pixel in the region of the joint ROI after subtraction of the adjacent tissue activity per pixel in the adjacent tissue ROI: score = ('joint ROI'-'adjacent ROI')/ 'adjacent ROI'. All counts were corrected for background, which was similar in all experiments.
IN VIVO ELUTION OF ${ }^{99 m}$ TC FROM INJECTED

LABELLED LYMPHOCYTE

Cell injection: Single cell suspensions $\left(50 \times 10^{6}\right.$ human blood lymphocytes in $300 \mu \mathrm{l}$ ), isolated and labelled with $63 \mathrm{MBq}$ of ${ }^{99 \mathrm{~m}} \mathrm{Tc}-\mathrm{HMPAO}$, as previously described, were injected intraperitoneally (ip) in five mice.

Animals: Six week old (SCID.bg17) mice were kept in a laminar flow hood throughout the experiments. The mice were monitored at six weeks for the absence of serum $\operatorname{IgM}$ by enzyme linked immunosorbent assay (ELISA).

Activity present in the whole mouse body was determined immediately after lymphocyte injection and 20 hours after injection. Mice were placed in an activimeter and the percentage of total activity remaining was determined. Mice injected ip with Tc-free HMPAO served as controls.

\section{STATISTICAL ANALYSIS}

To take into account the interdependence of the values obtained for each of the 12 joints of the eight patients with RA, we performed analysis of variance with two factors of Winer, ${ }^{11}$ to compare clinical or radiological scores with the scintigram scores. The intergroup factors were the subjects, the clinical score expressed as a categorical variable, and the scintigram results as the dependant variable. Comparison between the scintigram score obtained in the patients with early disease and that in the group of patients with long standing disease was by two-way analysis of variance where the intergroup factor was the duration of disease expressed as a categorical variable. The variation over time of the scintigram scores obtained at 30 minutes, three hours and 20 hours were compared using analysis of variance with one factor and repeated values. A p value less than 0.05 was considered as significant.

\section{Results}

STATIC JOINT SCINTIGRAM

We analysed 12 joints for each patient with RA, with a total of 96 joints. Fifty four joints presented clinical signs of inflammation, pain or swelling (table 2). The mean (SD) joint swelling score was $0.698(0.985)$, the mean (SD) pain score was $0.979(1.114)$ and the mean Larsen's score was $1.042(1.569)$. Of these 54 joints with active arthritis, 33 had a positive scintigram score, and 21 were 'false negative' joints defined as clinically active arthritis joints without any increased signal on the scintigram (table 2). The mean (SEM) scintigram score for the 96 joints at 30 minutes was $0 \cdot 164(0.037)$, at three hours it was 0.298 $(0.043)$, and at 20 hours after injection, 0.233 $(0.0044)$. The mean (SD) scintigram score for the 54 clinically active joints at 30 minutes was $0.476(0.37)$, at three hours it was 0.453 $(0.422)$, and at 20 hours after injection, 0.496 $(0 \cdot 40)$. Of the 42 joints without synovitis, only 12 had a positive scintigraphy. The predictive value of a positive joint scintigram score was 0.73 , which means that a positive scintigram is predictive of active arthritis. 
Table 2 Clinical, radiological and scintigram scores of affected (active) joints in eight patients with $R A$

\begin{tabular}{|c|c|c|c|c|c|c|c|}
\hline foints & $\begin{array}{l}R A \\
\text { duration }\end{array}$ & $\begin{array}{l}\text { Pain } \\
\text { scoret }\end{array}$ & $\begin{array}{l}\text { Swelling } \\
\text { score }\end{array}$ & $\begin{array}{l}\text { Larsen } \\
\text { score }\end{array}$ & SCINTI $30 \mathrm{~min}$ & SCINTI $3 h$ & SCINTI $20 \mathrm{~h}$ \\
\hline Patient 1: right wrist & 8 years & 1 & 1 & 3 & 0.09 & 0.83 & $1 \cdot 37$ \\
\hline left wrist & & 1 & 1 & 3 & 0 & $0 \cdot 76$ & $1 \cdot 32$ \\
\hline right elbow & & 3 & 3 & 3 & 0.9 & $1 \cdot 3$ & 0.34 \\
\hline left elbow & & 1 & 1 & 0 & 1.07 & 1.36 & $0 \cdot 16$ \\
\hline Patient 2: right wrist & 22 years & 0 & 0 & 5 & 0 & 0 & 0 \\
\hline left wrist & & 0 & 0 & 4 & 0 & 0.33 & 0 \\
\hline right shoulder & & 0 & 0 & 5 & 0 & 0 & 0 \\
\hline left shoulder & & 0 & 0 & 5 & 0 & 0 & 0 \\
\hline right knee & & 0 & 0 & 3 & 0 & 0 & 0 \\
\hline left knee & & 0 & 0 & 3 & 0 & 0 & 0 \\
\hline right hip & & 3 & 3 & 4 & 0.28 & 0.31 & 0.02 \\
\hline Patient 3: right wrist & 11 years & 1 & 1 & 1 & 0 & 0 & 0 \\
\hline left wrist & & 1 & 1 & 1 & 0 & 0 & 0 \\
\hline right elbow & & 1 & 1 & 0 & 0 & 0 & 0 \\
\hline left elbow & & 1 & 1 & 0 & 0 & 0 & 0 \\
\hline left shoulder & & 1 & 0 & 0 & 0 & 0 & 0 \\
\hline right ankle & & 2 & 0 & 0 & $0 \cdot 21$ & 0.5 & $0 \cdot 3$ \\
\hline left hip & & 1 & 0 & 0 & 0 & 0 & 0 \\
\hline Patient 4: right wrist & 12 years & 3 & 2 & 3 & 0.43 & 0.4 & $0 \cdot 3$ \\
\hline left wrist & & 3 & 2 & 3 & 0.57 & 0.41 & 0.38 \\
\hline right elbow & & 2 & 1 & 0 & 0.54 & 0.46 & $0 \cdot 38$ \\
\hline right shoulder & & 2 & 0 & 0 & 0 & 0 & 0 \\
\hline right knee & & 3 & 2 & 3 & $2 \cdot 13$ & 1.05 & $0 \cdot 4$ \\
\hline left knee & & 3 & 2 & 3 & 1.97 & 1.07 & 0.45 \\
\hline Patient 5: right wrist & 5 years & 2 & 1 & 3 & 0.92 & 0.97 & \\
\hline left wrist & & 2 & 1 & 3 & 0 & $0 \cdot 11$ & \\
\hline right elbow & & 2 & 1 & 3 & 0 & 0 & \\
\hline left elbow & & 2 & 1 & 3 & 0 & 0 & \\
\hline right ankle & & 2 & 0 & 0 & 0 & 0 & \\
\hline left ankle & & 2 & 0 & 0 & 0 & 0 & \\
\hline right knee & & 2 & 1 & 3 & $0 \cdot 18$ & 0.5 & \\
\hline left knee & & 2 & $i$ & 3 & 0.28 & 1.77 & \\
\hline Patient 6: right wrist & 8 months & 3 & 3 & 1 & 0.53 & $0 \cdot 26$ & 0.51 \\
\hline left wrist & & 3 & 3 & 1 & 0.42 & 0 & 0.58 \\
\hline right elbow & & 2 & 1 & 0 & 0 & 0 & 0 \\
\hline left elbow & & 2 & 1 & 0 & 0 & 0 & 0 \\
\hline right ankle & & 2 & 2 & 0 & 0 & $0 \cdot 82$ & $0 \cdot 3$ \\
\hline left ankle & & 2 & 2 & 0 & 0 & 0.74 & $1 \cdot 23$ \\
\hline right knee & & 3 & 3 & 0 & 0.09 & 0.46 & 0.32 \\
\hline left knee & & 3 & 3 & 0 & $0 \cdot 11$ & $0 \cdot 4$ & 0.44 \\
\hline Patient 7: right wrist & 10 months & 2 & 1 & 5 & 0.42 & 1 & 0.8 \\
\hline left wrist & & 2 & 1 & 5 & 0.26 & 0.82 & 0.64 \\
\hline left shoulder & & 2 & 0 & 0 & 0 & 0 & 0 \\
\hline right ankle & & 1 & 1 & 5 & 0 & 1.06 & 0.98 \\
\hline left ankle & & 1 & 1 & 5 & 0 & 0.55 & 0.55 \\
\hline Patient 8: right wrist & 4 years & 2 & 1 & 4 & $0 \cdot 27$ & $0 \cdot 1$ & 0 \\
\hline left wrist & & 0 & 1 & 3 & $0 \cdot 19$ & 0.05 & 0 \\
\hline right elbow & & 2 & 1 & 0 & 0.38 & 0.33 & 0 \\
\hline right shoulder & & 2 & 1 & 2 & 0 & 0 & 0 \\
\hline left shoulder & & 2 & 1 & 2 & 0 & 0 & 0 \\
\hline right ankle & & 2 & 3 & 0 & 0 & $0 \cdot 78$ & 0.86 \\
\hline left ankle & & 2 & 3 & 0 & 0 & 0.89 & 1.69 \\
\hline right knee & & 2 & 3 & 2 & 0 & 0.96 & $1 \cdot 24$ \\
\hline left knee & & 1 & 2 & 2 & 0 & $1 \cdot 17$ & 1.72 \\
\hline
\end{tabular}

†Scale of 0-3 (see text). SCINTI = joint scintigram score at 30 minutes, three hours and 20 hours after injection.

ASSOCIATION OF JOINT SCINTIGRAM AND JOINT EVALUATION

The scintigram score at 20 hours increased significantly when the clinical evaluation of pain or joint swelling score increased ( $F$ test $=3.073, p<0.002$ ). Scintigram scores at 30 minutes and three hours after injection were associated with an increased pain and swelling score but the association did not reach statistical significance. Figure 1 shows the

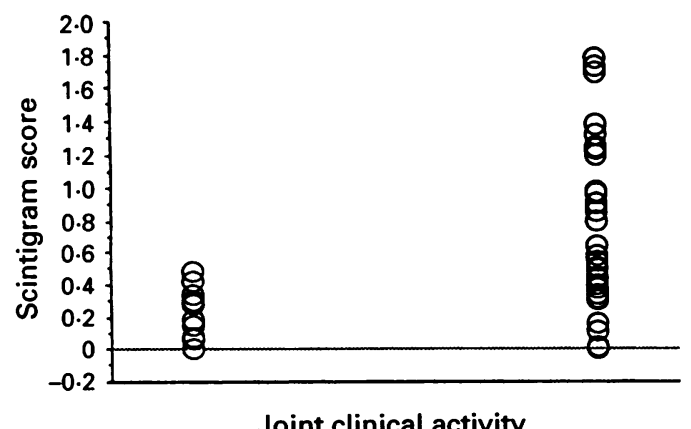
Figure 1 Foint scintigram score obtained 20 hours after injection of labelled lymphocytes in inflamed (right) and
inactive left) joints of eight $R A$ patients. Analysis was carried out by two way analysis of variance. $(p<0.002)$. scintigram score obtained at 20 hours in inflamed and inactive joints $(p<0.002)$. The scintigram scores obtained after 30 minutes, three hours and 20 hours were not associated with increased radiological scores. An increased joint swelling was associated with a high pain score $(p<0.0001)$ but not with the radiological score.

ASSOCIATION OF DISEASE DURATION AND KINETICS OF JOINT SIGNAL

Forty eight of the 96 joints studied were from four patients with RA with a disease duration of less than five years (eight months-five years). Figure 2A shows the variation over time of the signal obtained in active joints; the difference did not reach statistical significance (NS). In the joints of patients with early disease, we obtained an intense scintigram as early as 30 minutes (mean (SEM) $0.129(0.033)$ ), which increased at three hours $(0.353(0.065))$ and persisted at 20 hours $(0.372(0.082))$ as shown in figure 2C (NS). Examples of a joint scintigram image of a patient with early RA are shown in figure $3 \mathrm{~A}$ and $\mathrm{B}$. In three cases of early RA, we observed a linear vascular image on scintigrams obtained 30 minutes after 

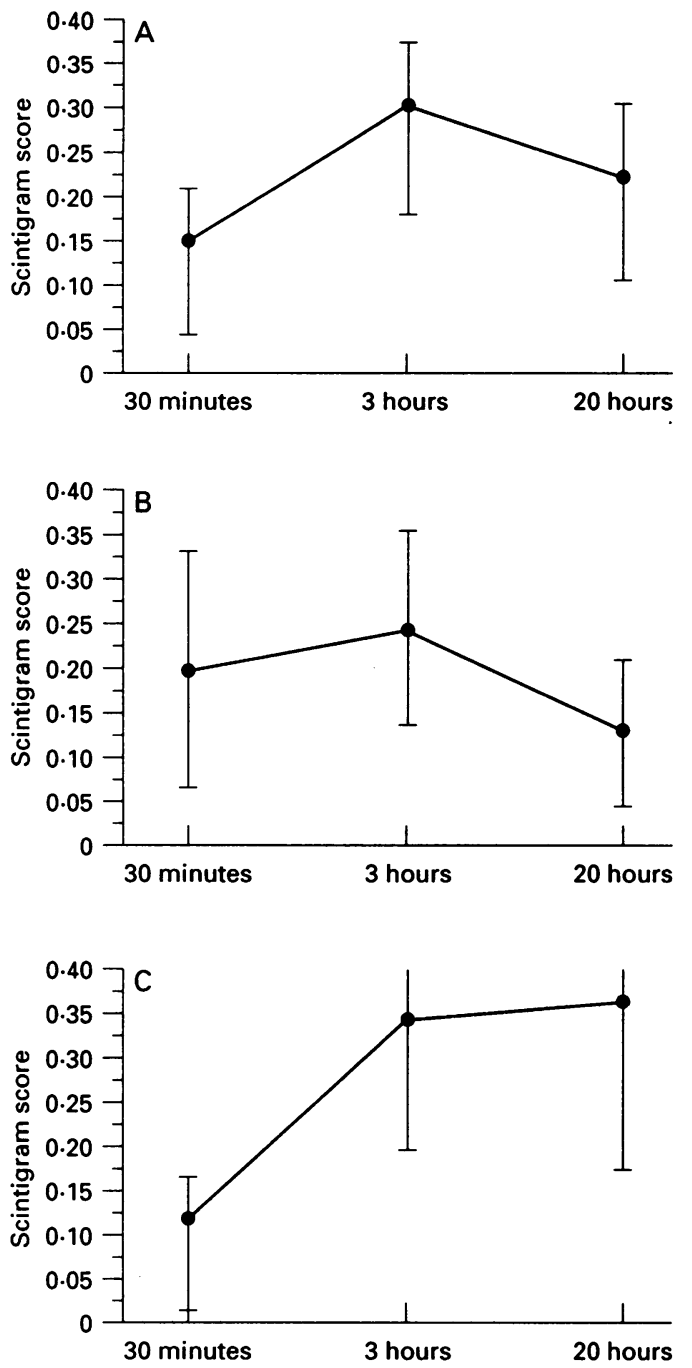

Figure 2 Scintigram scores (mean, SEM) for joints, obtained at 30 minutes, three hours and 20 hours after ip injection of radiolabelled lymphocytes. A: Kinetics of retention of lymphocytes in all 96 joints studied. No significant difference between the three mean values. $B:$ Changes in score for four patients with longstanding $R A$ (eight to 22 years). No significant difference between mean values. C: Score patterns for four patients with early $R A$ (eight months to five years). Mean value at 20 hours significantly different $(p<0.002)$.

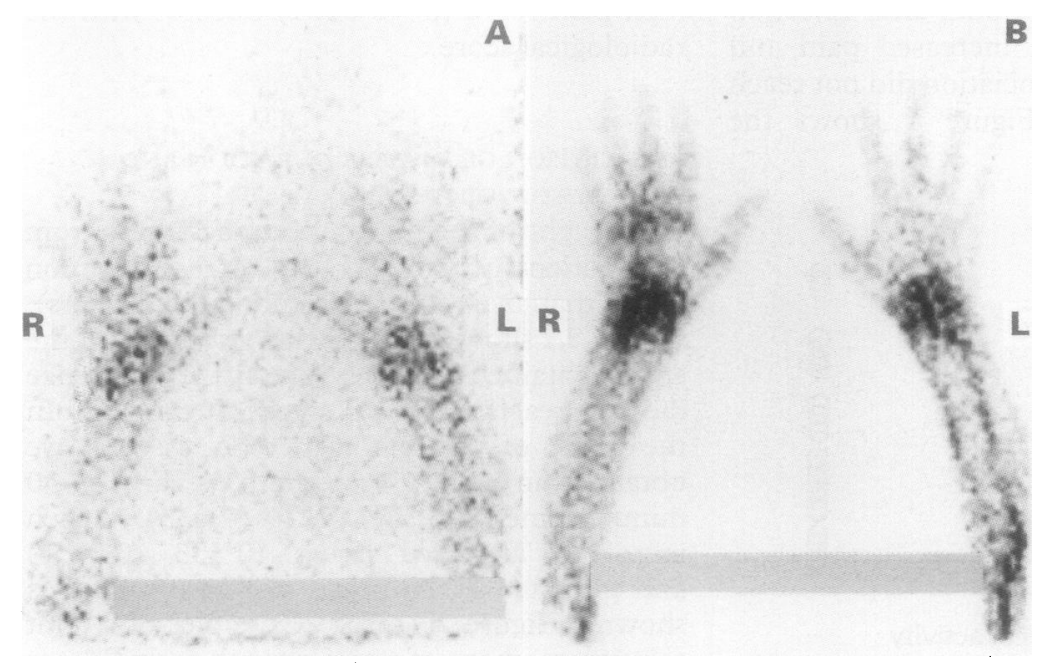

Figure 3 Radiolabelled lymphocyte scintigram of a patient with $R A$ and wrist arthritis. A: Images at 30 minutes showing early lymphocyte accumulation in the inflamed joints; B: same patient at three hours. injection (indicated by arrows on fig $4 \mathrm{~A}$ ). ROI on this region showed an increased count per pixel $(0.44)$ compared with ROI of the same surface taken on the joint signal ( 0.3 counts/ pixel). On the same patients 20 hours after injection, this linear image disappeared but ROI on the joint region showed a persistent increased activity $(0.55)$.

In contrast, in the joints of four patients with long standing disease (eight to 22 years), a comparable signal could be detected at 30 minutes $(0.199(0.066))$, but appeared less intense at three hours $(0.244(0.055))$ and decreased at 20 hours $(0.129(0.42))$ as shown in figure $2 \mathrm{~B}$. The variation over time did not reach statistical significance within this group of patients with RA. In contrast, the signal obtained at 20 hours was different between the two groups of patients ( $F$ test $=9.446$, $\mathrm{p}<0.002$ ), and the curve obtained in the group of patients with long duration RA tended to be distinct from patients with early disease.

RELEASE IN VIVO AND IN VITRO OF ${ }^{99 \mathrm{~m}} \mathrm{Tc}$ ACTIVITY FROM LABELLED LYMPHOCYTES The loss of radioactivity of the whole SCID mouse body 20 hours after injection was $36 \%$ of initial activity corrected for the half-life of technetium (range 22-45\%). No significant activity was observed in control mice injected with Tc-free HMPAO.

Fifty per cent of initial activity corrected for ${ }^{99 \mathrm{~m}} \mathrm{Tc}$ decay remained in human lymphocytes incubated in vitro for 20 hours.

CORRELATION OF JOINT SCINTIGRAM WITH SYNOVIAL HISTOLOGY

In three cases, the patients had surgery after the scintigraphy, and synovial histology was available. In two patients with early onset RA, an intense mononuclear cell infiltrate was present in the synovial tissue. The joint scintigram showed an intense and early signal. In the last patient, RA persisted for 20 years, and the progression of the disease was characterised by hip joint destruction which required a total arthroplasty. A scintigram of ${ }^{99 \mathrm{~m}}$ Tc-diphosphonate labelled bone showed an intense signal, but radiolabelled lymphocytes demonstrated a diminution of the scintigram signal (fig 5). The histology showed an intense fibrosis without lymphocyte infiltration.

\section{Discussion}

Precise assessment of disease activity in RA is difficult and has poor reproducibility. Joint pain is the result of effusion, local inflammation, capsule distention, and subchondral bone destruction. Furthermore, experience of pain is influenced by socio-economic status. There is a need for an objective investigational technique which could be applied to deep joints. For the first time, we have used radiolabelled lymphocyte joint scintigraphy to detect and quantify lymphocyte infiltration in the synovial membrane. 


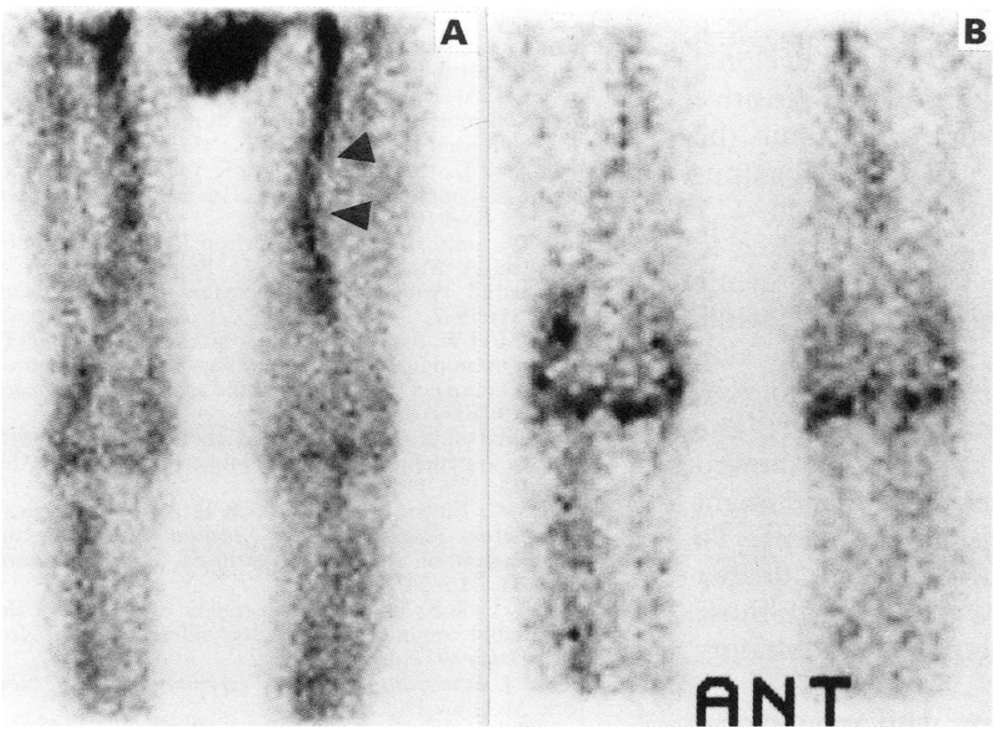

Figure 4 Radiolabelled lymphocyte scintigram showing the knees of a patient with $R A$ of early onset. A: Images at 30 minutes: note the vascular linear images (arrows), and the joint signal; B: same patient at three hours.

HMPAO is a chelating molecule which penetrates the cell membrane and binds intracellularly. The main application has been radiolabelling of polynuclear neutrophils to detect pyogenic infections. ${ }^{12}$ This method has recently been used to assess polynuclear migrations in inflamed rheumatoid joints. ${ }^{13}$ The use of ${ }^{99 \mathrm{~m}} \mathrm{Tc}-\mathrm{HMPAO}$ labelled cells seems to be safe, and no radiation damage to the leucocytes has been reported. The method appeared to be sensitive to detect synovitis, and preceded the clinical sign of joint inflammation. However, this imaging technique visualised neutrophil accumulation, whereas

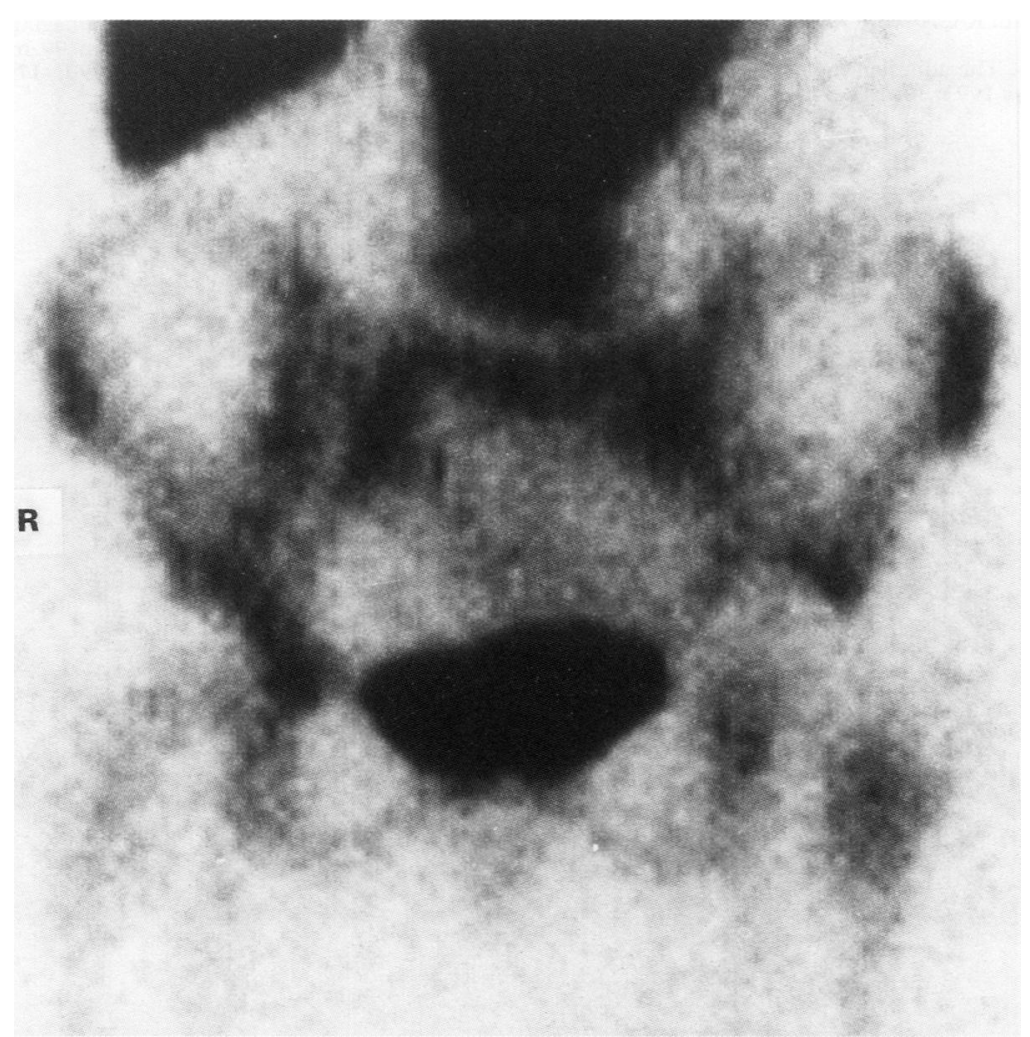

Figure $5 R A$ patient with 22 years disease duration, with hip arthritis: HMPAO radiolabelled lymphocyte scintigram showing a decrease in the signal on the left hip. rheumatoid synovium is infiltrated by lymphocytes. No difference in the joint scintigrams was observed between RA patients with different disease duration, and images with labelled granulocytes were obtained 22 hours after injection.

Using radiolabelled lymphocytes, we have obtained different results for joint scintigrams in RA. The images of lymphocyte retention in the affected joints were obtained as early as 30 minutes. The intensity of the image increased at three hours and decreased at 20 hours. The intensity of the joint scintigram correlated with the clinical evaluation of active synovitis in the affected joints. Moreover, patients with different disease durations did not show the same labelled-lymphocyte scintigram pattern: in patients with disease duration of less than five years, the images had an increased intensity at three hours and persisted at 20 hours. In contrast, in patients with long standing disease, lymphocyte retention in the joints was less intense at three hours, and decreased more significantly at 20 hours. To assess the blood contribution to the joint signal at 20 hours we measured the signal on a vascular ROI in patients with early disease and found that activity present at 30 minutes had disappeared at 20 hours. In contrast, the activity observed in the joint region persisted and increased at 20 hours, showing that this signal uptake was not related to activity circulated by the blood. Furthermore, to assess the survival of labelled lymphocytes, we injected human cells into SCID mice, which are unable to reject human cells. ${ }^{14}$ Twenty hours after injection, $64 \%$ of the injected activity persisted in the animals. Moreover, $50 \%$ of initial activity was eluted from labelled lymphocytes incubated for 20 hours. Thus the increased activity observed in the joint scintigram score in RA seems to be a reflection of retention of labelled lymphocytes in synovial tissue.

In addition, the kinetics of lymphocyte retention in the joint seems to differ with the stage of the disease. This might be a result of the variation in the intensity and specificity of adhesion molecules expression in the synovial membrane with time. ${ }^{4}$

Three patients in our study had surgery and synovial histology was available. In two cases, RA was of early onset and the synovial membrane was highly infiltrated by lymphocytes. The HMPAO scintigraphy showed an intense and early signal. In the last patient with destruction of the hip joint, histological analysis showed a non-specific fibrosis without lymphocyte infiltration; the ${ }^{99 \mathrm{~m}} \mathrm{Tc}-\mathrm{HMPAO}$ labelled lymphocyte scintigraphy showed a decreased signal from the hip. Thus the method seems to be a good reflection of the lymphocyte infiltration of the synovial membrane. In the study by Jones $e t a l$, a control group of three volunteers did not show any uptake 22 hours after an injection of HMPAO labelled leucocytes, and the direct injection of HMPAO in one RA patient did not show synovial uptake, confirming the specificity of the technique. ${ }^{15}$ 
Other isotope tracer methods have been used in RA. Joint scintigraphy with polyclonal human ${ }^{99 \mathrm{~m}} \mathrm{Tc}$-immunoglobulin was a sensitive tool to detect joint inflammation, but the specificity was low, and ${ }^{99 \mathrm{~m}} \mathrm{Tc}-\mathrm{IgG}$ accumulated in non-inflamed joints. ${ }^{16}{ }^{17}$ Indium-111 has been used as an intracellular marker to assess RA inflammation. ${ }^{8}$ The majority of the labelled cells were neutrophils, and while indium-111 leucocyte imaging had a high predictive value for joint inflammation in $R A$, the method was not specific for RA. ${ }^{18}$ The radiolabelled lymphocyte scintigraphy showed a low number of false positive joints, and might predict active synovitis within the joints. To assess the specificity of the method, further studies comparing the results in RA with those from other non-rheumatoid inflammatory arthropathies are needed.

Selective immunotherapy with monoclonal antibodies is being actively developed to treat refractory RA. Targets for the antibodies are numerous: activation antigens (CD4, CD5, CD25), class II HLA antigens, ICAM-1. ${ }^{19}$ Monoclonal labelled antibodies have been used to assess the retention of lymphocytes at the site of inflammation in RA patients treated by anti-CD4 antibodies and the scintigram showed early accumulation of the target cells in the inflamed joints. ${ }^{20}$ The HMPAO labelled lymphocyte scintigram might be useful in in vivo follow up of the antibody during selective immunotherapy in RA.

The results of our study suggest that radiolabelled lymphocyte joint scintigraphy could detect and localise active synovitis. More studies will be required to determine the specificity of this method.

1 Burmester G R, Yu D T, Irani A M. Ia + T-cells in synovial fluid and tissue of patients with RA. Arthritis Rheum 1981; 24: 1370-6.

2 Cronstein B N, Weissmann G. The adhesion molecules of inflammation. Arthritis Rheum 1993; 36: 147-57.
3 El-Gabawy H, Wilkins J. B-1 integrin expression in heumatoid synovial membranes: an immunohistologic tudy of distribution patterns. F Rheum 1993; 20: 231-7.

4 Johnson B A, Haines G K, Harlow L A, Koch A E. Adhesion molecule expression in human synovial tissue. Arthritis Rheum 1993; 36: 137-46.

5 Stamenkovic I, Stegagno M, Wright K A. Clonal dominance among T-lymphocyte infiltrates in arthritis. Proc Nat Acad Sci USA 1988; 85: 1179-83.

6 Hylton W, Smith-Burchnell C, Pelton B K, Palmer R G, Denman A M, Malkovsky $M$. Polyclonal origin of rheumatoid synovial T-lymphocytes. $B r \quad \mathcal{f}$ Rheumatol rheumatoid syn

7 De Bois M H W, Arndt J W, Velde van der E A, et al. 99Tc human immunoglobulin scintigraphy-a reliable method to detect joint activity in rheumatoid arthritis. $\mathcal{f}$ Rheumato 1992; 19: 1371-6.

8 Uno K, Matsui N, Nohira K, et al. Indium-111 leukocyte imaging in patients with rheumatoid arthritis. $\mathcal{F} \mathrm{Nucl} \mathrm{Med}$ 1986; 27: 339-44

9 Arnett F C, Edworthy S M, Bloch D A. The American Rheumatoid Association 1987 revised criteria for the classification of rheumatoid arthritis. Arthritis Rheum 1988; 31: 315-24.

10 Larsen A, Dale K, Eek M. Radiographic evaluation of RA and related conditions by standard reference films. Acta Radiol Diag 1977; 18: 488-91.

11 Winer B J. Statistical principles in experimental design. New York: McGraw-Hill, 1971

12 Peters A M, Osman S, Henderson B L, et al. Clinical experience with $99 \mathrm{Tc}$ hexamethylpropylene-amineoxime for labelling leucocytes and imaging inflammation. Lance 1986; ii: $946-9$.

13 Becker W, Borst U, Fishbach W, Pasurka B, Schafer R, Borner W. Kinetic data of in vivo labelled granulocytes in humans with a murine Tc $99 \mathrm{~m}$ labelled monoclonal antibody. Eur f Nucl Med 1989; 15: 361-66.

14 Tary-Lehmann M, Saxon A. Human mature T cells that are anergic in vivo prevail in SCID mice reconstituted with human peripheral blood. $\mathcal{F}$ Exp Med 1992; 175: with hum-16.

15 Jones A K, Al-Janabi M A, Solanki K, et al. In vivo leucocyte migration in arthritis. Arthritis Rheum 1991; 34: 270-5.

16 Breedveld F C, Kroonenburgh J P G, Camps J A J, Feitsma H I J, Markusse H M, Pauwels E K J. Imaging of inflammatory arthritis with Technecium $99 \mathrm{~m}$ labeled IgG. f Nucl Med 1989; 30: 2017-21.

17 Van der Lubbe P H M, Arndt J W, Calame W, Ferreira T C, Pauwels E K J, Breedveld F C. Measurement of synovial inflammation in rheumatoid arthritis with Technecium $99 \mathrm{~m}$ labeled human polyclonal immunoglobulin G. Eur f Nucl Med 1991; 18: 119-23.

18 Rydgren L, Wollmer P, Hultquist R, Gustafson T. Indium111 labelled leukocyte for measurement of inflammatory 111 labelled leukocyte for measurement of inflammatory

19 Kavanaugh A F, Nichols C A, Lipsky P E. Treatment of refractory RA with an anti CD54 (ICAM-1) monoclonal refractory RA with an anti CD54 (ICAM-1) monoclon

20 Becker W, Emmrich F, Horneff G, et al. Imaging rheumatoid arthritis specifically with technecium $99 \mathrm{~m}$ CD4-specific antibodies. Eur f Nucl Med 1990; 17 156-9. 